\title{
Corrigendum: Current Diagnosis and Management of Immune Related Adverse Events (irAEs) Induced by Immune Checkpoint Inhibitor Therapy
}

\author{
Vivek Kumar ${ }^{1}$, Neha Chaudhary ${ }^{2}$, Mohit Garg ${ }^{1}$, Charalampos S. Floudas ${ }^{1}$, Parita Soni ${ }^{1}$ \\ and Abhinav B. Chandra ${ }^{3 *}$ \\ ${ }^{1}$ Department of Medicine, Maimonides Medical Center, Brooklyn, NY, USA, ${ }^{2}$ Department of Pediatrics, Maimonides Medical \\ Center, Brooklyn, NY, USA, ${ }^{3}$ Medical Director, Yuma Regional Cancer Center, Yuma, AZ, USA
}

Keywords: check point inhibitors, immune related adverse events, nivoulmab, pembrolizumab, ipilimumab

OPEN ACCESS

Edited and reviewed by: Raquel Abalo,

Universidad Rey Juan Carlos, Spain

*Correspondence:

Abhinav B. Chandra abhinavbck@hotmail.com

Specialty section:

This article was submitted to Pharmacology of Anti-Cancer Drugs,

a section of the journal

Frontiers in Pharmacology

Received: 17 April 2017 Accepted: 11 May 2017 Published: 31 May 2017

Citation:

Kumar V, Chaudhary N, Garg M, Floudas CS, Soni $P$ and Chandra $A B$

(2017) Corrigendum: Current

Diagnosis and Management of

Immune Related Adverse Events

(irAEs) Induced by Immune

Checkpoint Inhibitor Therapy.

Front. Pharmacol. 8:311.

doi: 10.3389/fphar.2017.00311

\section{A corrigendum on}

Current Diagnosis and Management of Immune Related Adverse Events (irAEs) Induced by Immune Checkpoint Inhibitor Therapy

Kumar, V., Chaudhary, N., Garg, M., Floudas, C. S., Soni, P., and Chandra, A. B. (2017). Front. Pharmacol. 8:49. doi: 10.3389/fphar.2017.00049

\section{ERROR IN TABLE 1}

The Therapeutic Status for Tremelimumab in Table 1 was incorrect. In the original article it was: FDA approved in malignant mesothelioma (2015)

Corrected: Tremelimumab was granted orphan drug status in 2015 for the treatment of malignant mesothelioma but is not FDA approved yet.

\section{ERROR IN ABSTRACT}

In the original article, there was an error: The indications of immune checkpoint inhibitors (ICIs) are set to rise further with the approval of newer agents like tremelimumab and atezolimumab for use in patients with advanced stage mesothelioma and urothelial carcinoma respectively.

Corrected sentence: The indications of immune checkpoint inhibitors (ICIs) are set to rise further with the approval of newer agent like atezolimumab for use in patients with advanced stage urothelial carcinoma.

\section{ERRORS IN SUPPLEMENTARY TABLE S1}

Original Article: Ribas et al. on Tremelimumab in grade $>3$ toxicities Endocrine adverse effects is $6(2)$ 
Corrected: Not reported (NR)

Original Article: Massard et al. on Durvalumab in grade $>3$ toxicities Diarrhea is NR

Corrected: 0 (0).

The authors apologize for these errors and state that this does not change the scientific conclusions of the article in any way. The original article and supplementary material has been updated with these corrections.
Conflict of Interest Statement: The authors declare that the research was conducted in the absence of any commercial or financial relationships that could be construed as a potential conflict of interest.

Copyright (c) 2017 Kumar, Chaudhary, Garg, Floudas, Soni and Chandra. This is an open-access article distributed under the terms of the Creative Commons Attribution License (CC BY). The use, distribution or reproduction in other forums is permitted, provided the original author(s) or licensor are credited and that the original publication in this journal is cited, in accordance with accepted academic practice. No use, distribution or reproduction is permitted which does not comply with these terms. 